\title{
Low-Carbon Watershed Management: Potential of Greenhouse Gas Reductions from Wastewater Treatment in Rural Vietnam
}

\author{
Lan Huong Nguyen, ${ }^{1}$ Geetha Mohan, ${ }^{2}$ Pu Jian, ${ }^{2}$ \\ Kazuhiko Takemoto, ${ }^{3}$ and Kensuke Fukushi ${ }^{4}$ \\ ${ }^{1}$ Graduate Program in Sustainability Science-Global Leadership Initiative (GPSS-GLI), Graduate School of Frontier Sciences, \\ The University of Tokyo, Chiba 277-8563, Japan \\ ${ }^{2}$ Integrated Research System for Sustainability Science (IR3S), The University of Tokyo, Tokyo 113-8654, Japan \\ ${ }^{3}$ The United Nations University Institute for the Advanced Study of Sustainability, Tokyo 150-8925, Japan \\ ${ }^{4}$ The University of Tokyo Institutes for Advanced Studies (UTIAS), Integrated Research System for Sustainability Science (IR3S), \\ The University of Tokyo, Tokyo 113-8654, Japan
}

Correspondence should be addressed to Lan Huong Nguyen; lanhuong1184@gmail.com

Received 29 February 2016; Revised 5 August 2016; Accepted 14 August 2016

Academic Editor: Claudio Cameselle

Copyright (C) 2016 Lan Huong Nguyen et al. This is an open access article distributed under the Creative Commons Attribution License, which permits unrestricted use, distribution, and reproduction in any medium, provided the original work is properly cited.

\begin{abstract}
Currently in many cities and rural areas of Vietnam, wastewater is discharged to the environment without any treatment, which emits considerable amount of greenhouse gas (GHG), particularly methane. In this study, four GHG emission scenarios were examined, as well as the baseline scenario, in order to verify the potential of GHG reduction from domestic wastewater with adequate treatment facilities. The ArcGIS and ArcHydro tools were employed to visualize and analyze GHG emissions resulting from discharge of untreated wastewater, in rural areas of Vu Gia Thu Bon river basin, Vietnam. By applying the current IPCC guidelines for GHG emissions, we found that a reduction of GHG emissions can be achieved through treatment of domestic wastewater in the studied area. Compared with baseline scenario, a maximum 16\% of total GHG emissions can be reduced, in which $30 \%$ of households existing latrines are substituted by Japanese Johkasou technology and other $20 \%$ of domestic wastewater is treated by conventional activated sludge.
\end{abstract}

\section{Introduction}

Vietnam in recent years, after economic reforms (Doi Moi, 1986), has been experiencing rapid economic growth, with an average annual growth rate of $5.4 \%$ in gross domestic product (GDP). The GDP per capita in Vietnam is projected to reach around 2333 USD in the year 2030, which might bring an increase in energy consumption and impel a corresponding increase in GHG emissions. The energy sector is the largest source of Vietnam GHG emissions. In 2000, GHG emissions proportion from energy sector is $35 \%$, equivalent to 52.8 $\mathrm{TgCO}_{2}$ eq of total $150.9 \mathrm{TgCO}_{2}$ eq emissions [1], and will continue to increase as projected until 2030. Total emissions from energy, agriculture, land use, land use change, and forestry sectors are projected to be 169.2, 300.4, and 515.8
$\mathrm{TgCO}_{2}$ eq in 2010, 2020, and 2030, respectively. Energy sector accounts for $91.3 \%$ of projected total emissions for 2030 .

The waste and wastewater sector has a small share in total GHG emissions of the country. However, this sector emission is likely to increase, due to population growth and the lack of wastewater treatment in cities and as well in rural areas. The major GHGs including $\mathrm{CH}_{4}$ and $\mathrm{N}_{2} \mathrm{O}$ can be produced and emitted at many stages from sources and final disposal along the discharge pathways [2]. Currently, the urban population is $28 \%$, and accessing of drainage and wastewater treatment facilities is still too low compared to accessing of drinking water supply services. There is only 40 to $50 \%$ of urban population served by sewage system, in which only $10 \%$ of the wastewater collected is treated with adequate treatment technology before entering the environment [3]. The rest of urban 
wastewater is discharged into natural water bodies. Under tropical climate with relatively high temperature throughout the year, anaerobic processes take place to different extents and methane is released to the atmosphere [4]. Meanwhile in rural areas, the most common sanitation practice is household latrines. Household wastewater (including gray water and black water) is collected in underground chambers and seepage to ground or discharged directly to farm land or gardens, eventually entering open water bodies. The high methane conversion factor (MCF) value of household latrines $[4,5]$ indicates a significant amount of methane emission from this treatment facility. Thus, having a proper wastewater treatment facility would reduce GHG emissions from domestic wastewater discharge and handling. However, the inventory of GHG emission from wastewater sector as well as options to reduce GHG emission in the sector was not described in any of climate change mitigation policies of the country. Also, taking the sectoral approach by targeting each sector (i.e., emissions targeted in VGGS [6]) in the economy might result in unbalance of development in the sector because many of the sectors are highly independent on each other especially the nexus of water and energy sector.

Methane emission from wastewater treatment is among the major sources of $\mathrm{GHG}$ emissions besides $\mathrm{CO}_{2}$ and $\mathrm{N}_{2} \mathrm{O}$. Methane emission results from the two main routes: the decomposition of degradable organic under anaerobic condition and the air exposure of flow containing dissolved $\mathrm{CH}_{4}$. Under anaerobic condition, organic matters contained in wastewater are decomposed by anaerobic bacteria (e.g., the denitrification or dephosphorization process) resulting in the generation of $\mathrm{CH}_{4}$. Also, $\mathrm{CH}_{4}$ dissolved in wastewater could be released into atmosphere via surface exposure. Recent research on GHG emissions from domestic wastewater was seen mostly in small scale or some specific treatment processes. Work conducted by Ma et al. [7] is among few studies that focus on the general condition of domestic wastewater using the IPCC methods for GHG emissions inventory for wastewater discharge and handling (hereafter called IPCC method). This study found that the emissions from domestic wastewater treatment could be reduced by $10 \%$ or $0.0763 \mathrm{Mt}$ in the year 2020 scenarios. However this study as well as IPCC method is significant regarding trend and peak of GHG emissions; the allocation of GHG from spatial dimension was not considered especially from emissions from the watershed. In a study by Galloway et al. [8], emission from watershed was analyzed because watersheds have structural and functional characteristics that can reflect and influence how humans interact within the watershed system. In this analysis, the watershed is considered as one of the four major reservoirs, namely, atmosphere, watershed, coastal and shelf region, and open oceans. The result of this study shows the major source of $\mathrm{N}$ is from $\mathrm{N}$-fertilizer input. However, this study did not include inputs from sewage discharge to the watershed. Another related study from [9] examined the life cycle GHG emissions from sewage sludge treatment in the Tai Lake Watershed in China. This study selects different sludge treatment and disposal processes to reduce emissions in the watershed and suggests the optimum choice for the Tai Lake Watershed. The proportion of GHG emission from this process calculates about $40 \%$ of total emission from sewage treatment and handling $[10,11]$. The case of Tai Lake is much different from other developing countries, where sewage discharged without proper treatment and became the major source of GHG emissions from rivers and streams. Therefore, it is important to study the GHG emissions from wastewater discharge and handling in the watershed to provide the optimum solution of the wastewater system for the river basin.

This paper describes briefly the status of water and wastewater sector in Vietnam followed by the estimation of GHG reduction from domestic wastewater by providing adequate wastewater treatment facilities under different emission scenarios for the $\mathrm{Vu}$ Gia Thu Bon river basin. GHG reductions from domestic wastewater handling and disposal from subwatershed are then analyzed using ArcGIS. Finally this paper addresses uncertainties in the calculation methods and then discusses the economical aspect of the proposed scenarios.

1.1. Vietnam Water and Wastewater Sector. Vietnam has relatively abundant water resources including surface and ground water existing in rivers, lakes, artificial reservoirs, and underground aquifers. Its dense river network consists of 2,372 rivers which are over 10 kilometers long and includes 109 main rivers with the total area of river basins $1,167,000 \mathrm{~km}^{2}$. The total annual river flow volume is approximately 847 billion $\mathrm{m}^{3}$. There are many natural lakes, ponds, lagoons, and pools, which are not sufficiently identified. It is estimated that the total area of ponds and lakes is merely $1,500 \mathrm{~km}^{2}$. Groundwater resource is recognized as significant reserve with estimated volume of 48 billion $\mathrm{m}^{3}$ per year.

With increasing economic growth in Vietnam in recent decades, declining water quality in the basins is becoming an acute problem. Urban areas are subject to serious degradation in water quality, whilst rural area faces problem of clean water access. With the rapid economic development, it is estimated that the urban population will double, which poses high pollution risk to the water resources. Sustainable development has to ensure water quality and environmental protection that would minimize the environmental impact. Domestic wastewater treatment is one of the first priorities; however, the lack of investment and payment for wastewater services poses challenges for the implementation of the system [3]. In addition, water is an energy intensive sector, which requires a large consumption of electricity for treatment of drinking water, wastewater, and water transportation. A number of studies in different countries and cities like India [12], China [13], Japan [14], Australia [15], and USA [16] have shown that energy consumption for water and wastewater treatment increases with higher GDP. In urban areas, energy consumption in water and wastewater sector is relatively higher than the country average. For instance, in California City, the water sector consumes $13 \%$ of the total electricity consumption of the city. The city Tokyo exhibits the similar case with an energy consumption of $903 \mathrm{kWh} / \mathrm{cap} / \mathrm{yr}$. This trend clearly indicates that the energy consumption for water and wastewater treatment increases with higher GDP relatively higher than the country average. 
TABLE 1: Socioeconomic indicator of Quang Nam province, 2012.

\begin{tabular}{lccc}
\hline Socioeconomic indicators & Unit & Quang Nam & National \\
\hline $\begin{array}{l}\text { GDP per capita at current price } \\
\text { Average monthly income per } \\
\text { capita at current price }\end{array}$ & USD & 1,248 & 1,749 \\
$\begin{array}{l}\text { Household living under poverty } \\
\text { line }\end{array}$ & $\%$ & 17.93 & 93 \\
Literacy rate & $\%$ & - & 14.2 \\
Household access to electricity & $\%$ & 95.57 & 97.1 \\
$\begin{array}{l}\text { Household access to hygienic } \\
\text { latrine }\end{array}$ & $\%$ & 80.0 & 77.4 \\
Urban population & $\%$ & 19.18 & 31.84 \\
Rural population & $\%$ & 80.92 & 68.16 \\
\hline
\end{tabular}

${ }^{1}[19]$.

${ }^{2}[20]$.

Vietnam has successfully progressed in improving its water supply situation over the past decades. The proportion of population using an improved drinking water source is increased by $28 \%$ from 1990 to 2010 [17]. According to Ministry of Construction [3, 18], until the year 2010, 18.15 million people could have access to drinking water, accounting for $69 \%$ of the total urban population, with an average water amount of $80-90 \mathrm{~L} /$ person/d in urban and $120-130 \mathrm{~L} /$ person/d in large cities. Assuming it takes about $0.3 \mathrm{kWh}$ energy for producing $1 \mathrm{~m}^{3}$ clean water from surface water and $0.6 \mathrm{kWh}$ for reclaimed wastewater, the amount of energy consumption for treatment of water supply is approximately $800 \mathrm{MWh}$ /day and 1,600 MWh/day to treat wastewater generated from the urban population. Currently in many cities and rural areas of Vietnam, wastewater is not treated and discharged to the environment, which emits considerable amount of methane. In addition, wastewater discharge and wastewater treatment facilities produce the major greenhouse gases, carbon dioxide $\left(\mathrm{CO}_{2}\right)$, methane $\left(\mathrm{CH}_{4}\right)$, and nitrous oxide $\left(\mathrm{N}_{2} \mathrm{O}\right)$. Therefore, sustainable wastewater treatment technology has to consider the balance of energy input as well as emission from water treatment process.

\section{Materials and Methods}

2.1. Study Area. The study site locates at the Vu Gia Thu Bon river basin, the most important social-economic hub of the Central Vietnam. The river system originates from mountains of the Kon Tum province and flows through Quang Nam province and Da Nang city before discharging to the sea. Two main rivers from the system named Vu Gia and Thu Bon both originates from the Truong Son mountain range (Figure 1). This river basin is the major water resource for the region especially of high potential for hydropower development. The area with $75 \%$ of hills and mountains is favored for small and medium water resources development project including small hydropower and decentralized water resource management.

The economic development in this region is however very low, compared to the other river basins such as Red River basin in the north and Dong Nai river basin in the south. Quang Nam province covers the largest areas of the three main provinces in the Vu Gia Thu Bon river basin. As shown in Table 1, Quang Nam has a relatively low GDP per capita compared to the national average with 1,248 US dollars [20]. The ethnic minorities that have a large population living below the poverty line inhabit the mountainous districts. Lack of electricity for development as well as water supply and sanitation has been seen as the most vulnerable issue of this region.

Household pour-flush pit latrines are seen as the most common wastewater treatment facility in this region, which is similar to other parts of the country. Rural households usually install underground chambers to collect wastewater mostly black water. Generally, black water is collected and seepage into the ground, sludge, and feces is settled while gray water is discharged to gardens or farmland (Figure 2). In some cases especially in towns, or wealthy households, wastewater collected in septic tanks is mixture of black and gray water or if there is presence of sewer, septic tanks only receive black water. In addition due to lack of sludge treatment infrastructure and service, sludge is not emptied regularly. The house owners usually empty septic tanks when they are full which can take from 1 to 10 years [25]. There are several micro credit facilities to rural household to borrow a certain amount of cash average 600 US dollars, to construct latrine with zero percentage of interest rate from the local government funds.

\subsection{Methodology}

2.2.1. Watershed Delineation. Two digital maps, DEM, and land use in raster format are needed to derive watershed characteristics. DEM resolution of $30 \mathrm{~m}$ is derived from digital topographic map, scale 1:50000. Both land use and topographic map are obtained from Quang Nam Natural Resource and Environment Department. Watershed boundaries are extracted from DEM using ArcHydro (Figure 3). The study area boundaries were identified that cover 103 watersheds with total area of $2,924 \mathrm{~km}^{2}$.

The land use map (Figure 4) and subwatershed map are integrated so that the residential area is covered within the watershed boundaries (Figure 5). Population was obtained at communal level from Quang Nam Statistical Office, and then total population living in designated residential area in each of the watersheds was calculated (Figure 6).

\subsubsection{Methane Emission Analysis from Domestic Wastewater} Treatment and Discharge. GHG emissions from watersheds are calculated based on GHG protocol and IPCC Guidelines for National Greenhouse Gas Inventories [4]. The boundary of this study includes direct GHG emissions, that is, methane emission from domestic wastewater treatment and indirect GHG emissions through electricity import for system operation (Figure 7). In scope of this study, $\mathrm{CO}_{2}$ and $\mathrm{N}_{2} \mathrm{O}$ emissions from wastewater treatment are not considered. The $\mathrm{CO}_{2}$ emission is biogenic origin that is part of natural carbon cycle and does not contribute to global warming. Therefore it is not included in natural GHG emissions inventory. The 


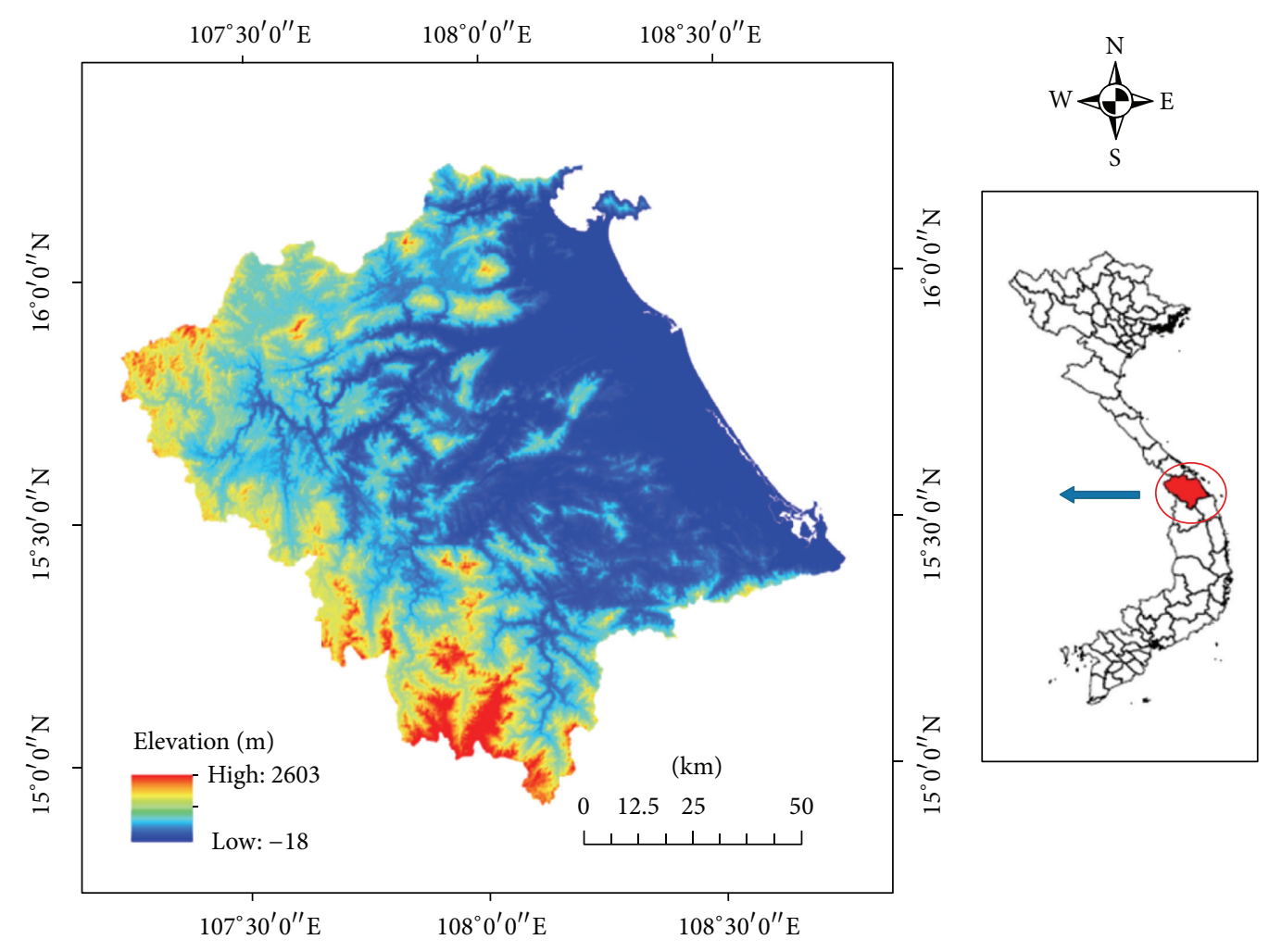

Figure 1: Vu Gia Thu Bon river basin in central Vietnam.

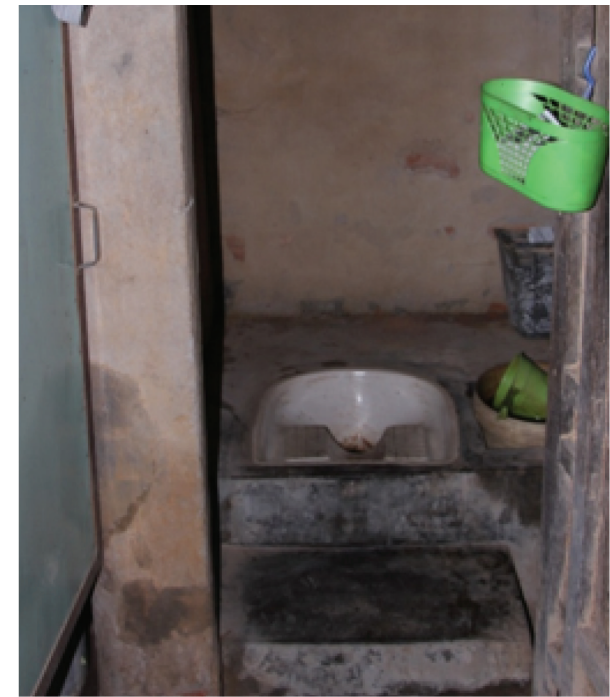

(a)

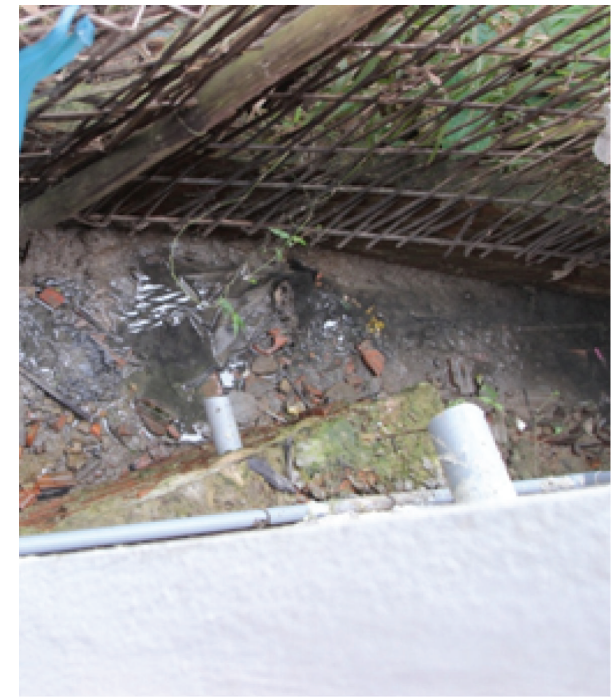

(b)

Figure 2: Typical household pour-flush pit latrine (a). Black water overflow and gray water discharged to backyard (b) (photo taken by author).

$\mathrm{N}_{2} \mathrm{O}$ emission is not included because of insufficient data and large uncertainties associated with the IPCC default emission factors for $\mathrm{N}_{2} \mathrm{O}$ from effluent [4]. The system boundary and wastewater discharge pathways are shown in Figure 7.

The total $\mathrm{CH}_{4}$ emission from domestic wastewater discharged in watershed is calculated based on the following equations.
Total $\mathrm{CH}_{4}$ emission from domestic wastewater discharged in watershed $i$ is

$$
\mathrm{CH}_{4 i}=\left[\sum_{k, j}\left(U_{k} \times T_{k, j} \mathrm{EF}_{j}\right)\right]\left(\mathrm{TOW}_{i}-S_{i}\right)-R_{i}
$$




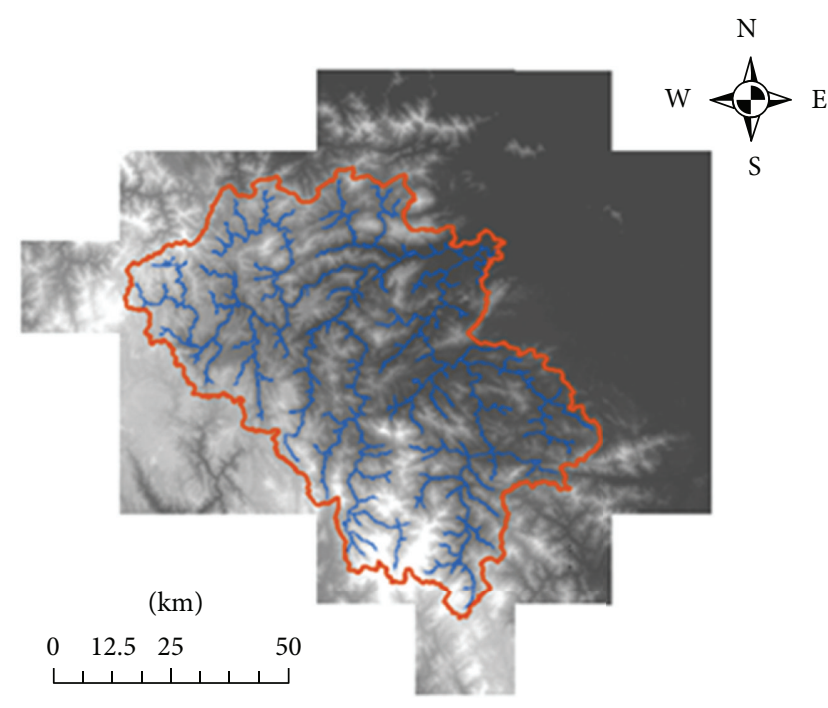

Figure 3: Watershed delineation using ArcHydro 9.1.

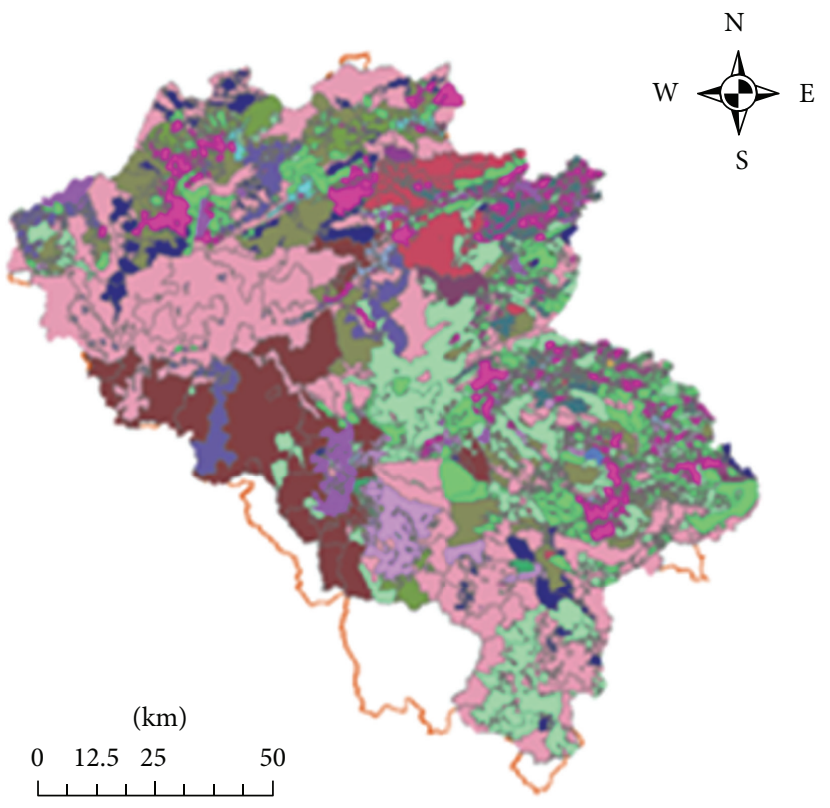

Figure 4: Land use map.

where $\mathrm{CH}_{4 i}$ is $\mathrm{CH}_{4}$ emission in inventory year in watershed $i$, $\mathrm{kg} \mathrm{CH}_{4}$ /year, $\mathrm{EF}_{j}$ is emission factor of treatment pathway $j, \mathrm{~kg} \mathrm{CH}_{4} / \mathrm{kg} \mathrm{BOD}$ (Section 2.3.2), $\mathrm{TOW}_{i}$ is total organically degradable carbon in domestic wastewater discharged in watershed $i, S_{i}$ is organic component removed as sludge in inventory year, $\mathrm{kg} \mathrm{BOD} /$ year, $U_{k}$ is fraction of population in income group $k$ in inventory year, $U_{k}=1, T_{k, j}$ is degree of utilization of treatment pathway $j$, and $R_{i}$ is amount of $\mathrm{CH}_{4}$ recovered in inventory year, $\mathrm{kg} \mathrm{CH}_{4} /$ year.

There are several assumptions to the calculation of total methane emission as follows:

Fraction of degradable organic component removed as sludge $S_{i}=0$.

No recovery or flaring of methane $R_{i}=0$.

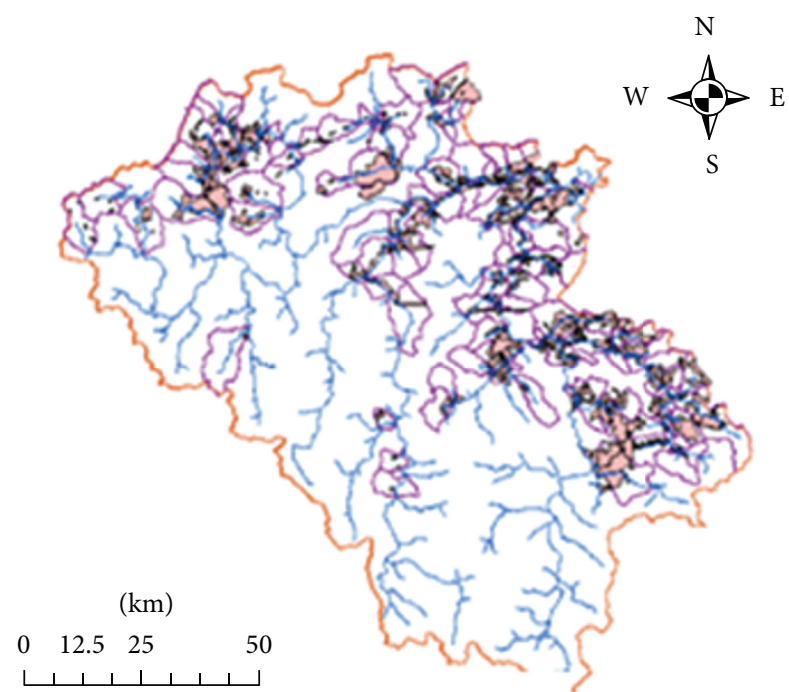

FIGURE 5: Rural settlement designated in watersheds.

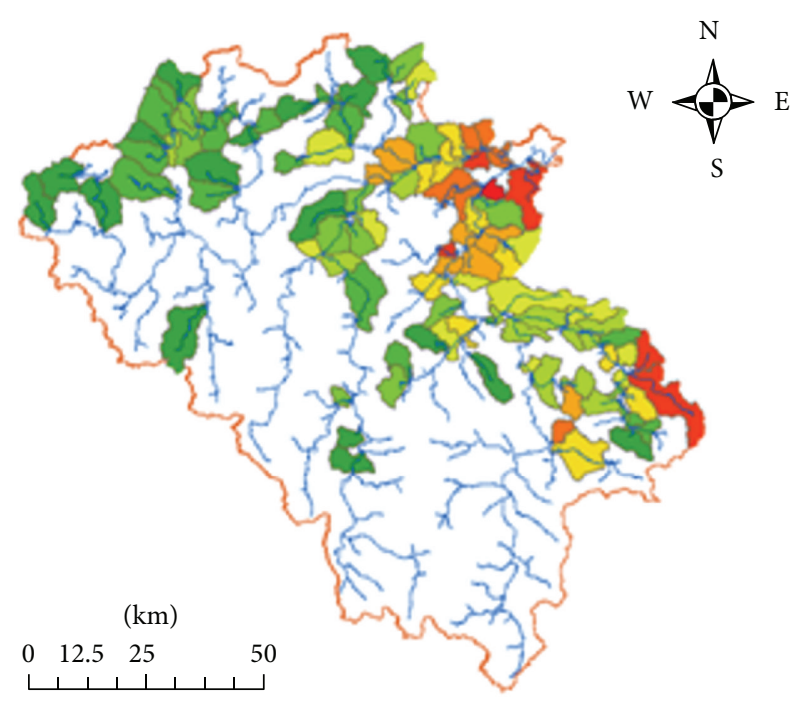

FIgure 6: Population density (2012).

\subsection{Data}

2.3.1. Activity Data. We used IPCC default value for the amount of organics content of domestic wastewater. Because the value of $\mathrm{BOD}$ in domestic wastewater depends on the wastewater treatment system, the quantity of discharged wastewater, and the degree of utilization of the wastewater treatment, the lower value of $40 \mathrm{~g} /$ person/day was chosen for the analysis. Also the gross domestic product (GDP) is an important indicator for the economic development of the region, the increasing of GDP in economic development impels the increasing of BOD in domestic wastewater. Thus, according to expert judgment, the BOD value project for the next 30 years was assumed as $60 \mathrm{~g} /$ person/day.

2.3.2. Wastewater Treatment Pathways and Emission Factors. The treatment options included in the analysis cover 


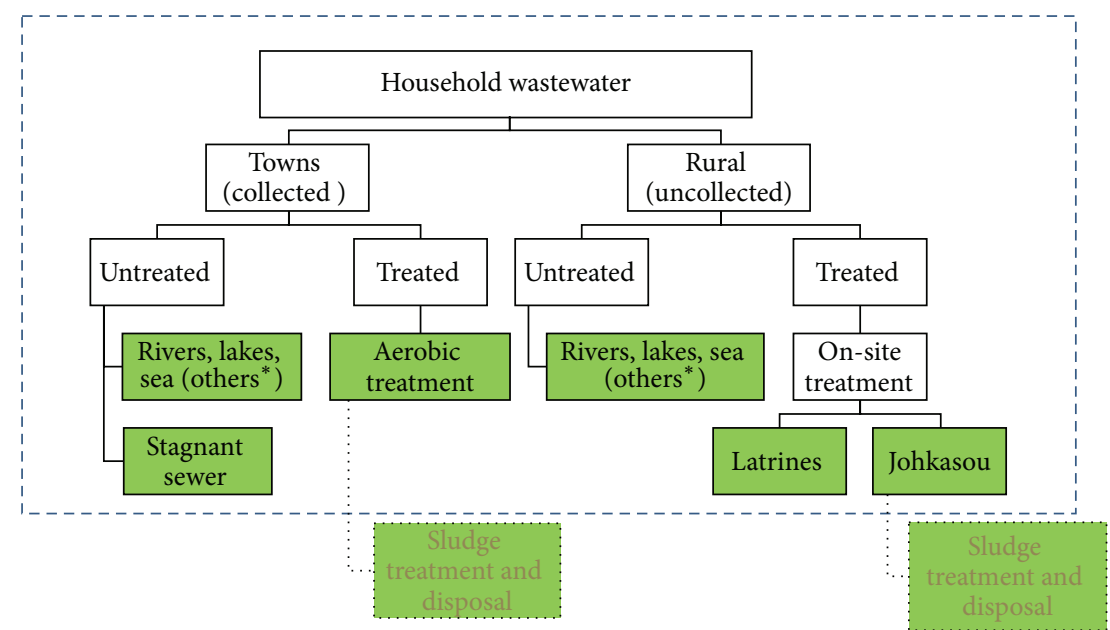

- - - Boundary of GHG emissions sources in wastewater treatment

GHG emission source

Figure 7: System boundary and wastewater treatment pathways. * refers to the term "others" as indicated in Table 3

household latrines, onsite advanced treatment Johkasou, and centralized conventional aerobic treatment. The emission factor from different treatment pathways is calculated as follows:

$$
\mathrm{EF}_{j}=B_{o} \times \mathrm{MCF}_{j}
$$

where $\mathrm{EF}_{j}$ is the emission factor of treatment pathway $j, \mathrm{kgCH}_{4} / \mathrm{kgBOD}$, and $B_{0}$ is the maximum $\mathrm{CH}_{4}$ producing capacity, $\mathrm{kg} \mathrm{CH}_{4} / \mathrm{kg} \mathrm{BOD}$. The IPCC default value is $0.6 \mathrm{~kg} \mathrm{CH} / \mathrm{kg} \mathrm{BOD}$ and $\mathrm{MCF}_{j}$ is the methane correction factor of treatment pathway.

The methane correction factors for household latrines, sewer, and centralized aerobic treatment were selected from the IPCC guidelines. The value was 0.7 for household latrines, 0.5 for sewer system, and 0.2 for conventional activated sludge treatment.

In the project scenarios of low population density especially in the upstream of the basin, the Japan decentralize treatment system (Johkasou) was selected. The Johkasou unit can perform tertiary treatment to ensure the effluent BOD below $20 \mathrm{mg} / \mathrm{L}$. Originated in Japan, until the year 2010, the Johkasou system has been serving approximately 30 million people with $9 \%$ of total population [27]. The results of Johkasou treatment performance were shown in Table 2. These results were obtained from the standardized Johkasou with the capacity of 1 to $50 \mathrm{~m}^{3} /$ day. The influent was the domestic wastewater with similar characteristic to the household wastewater in the studied region.

The emission calculated for Johkasou system includes methane and indirect emission from electricity consumption. Emission factor used was $1.84 \mathrm{kgCH}_{4} /$ person/year [28] and energy consumption was $101 \mathrm{~W}$ for the ten-person Johkasou unit [29]. Grid emission factor for Vietnam grid was $0.56 \mathrm{tCO}_{2} / \mathrm{MWh}$ and was expected to increase to $0.72 \mathrm{tCO}_{2} / \mathrm{MWh}$ in year $2030[30]$.
TABLE 2: Johkasou system wastewater treatment performance (source: [21, 22]).

\begin{tabular}{lccc}
\hline Parameters & Influent & Effluent & $\begin{array}{c}\text { Vietnam standard } \\
\text { for domestic } \\
\text { effluent [23] }\end{array}$ \\
\hline COD, mg/L & $200-400$ & $22-50$ & - \\
BOD, mg/L & $150-200$ & $11-20$ & 30 \\
TSS, mg/L & $80-200$ & $1.6-50$ & 50 \\
$\mathrm{NH}_{4}-\mathrm{N}, \mathrm{mg} / \mathrm{L}$ & $20-40$ & $2-5$ & 5 \\
T-P, mg/L & $6-8$ & $4-6$ & 6 \\
Coliform, & $0.1 \times 10^{6}-2 \times 10^{9}$ & $2900-3000$ & 3000 \\
MPN/100 mL & & & \\
\hline
\end{tabular}

2.3.3. Scenario Description. The model simulates carbon emissions for 30 years from January 2012 to December 2041 under four scenarios. Scenarios description is provided in Table 3.

According to population projection in the region until 2050 , population growth rate is assumed to be at $0.5 \%$ for all scenarios. In addition, due to GDP increasing and lifestyle improvement in the region, BOD value in domestic wastewater increases from 40 to $60 \mathrm{~g} / \mathrm{cap} /$ day. Upon baseline scenario, four mitigation options to reduce GHG emissions from wastewater discharge and treatment are proposed, namely, scenario 1 to scenario 4 . In relation to climate change scenarios developed for Vietnam, scenarios 1 and 2 represent the medium emission scenario (B2 (IPCC Fourth Assessment Report, B2 family scenario: continuously increasing population, but at a rate lower than A2; the emphasis being on local rather global solutions to economic, social, and environmental sustainability; intermediate levels of economic development; less rapid and more diverse technological change than in B1 family (medium emission scenario).)), while scenarios 3 and 4 represent the low emission scenario (B1 
TABLE 3: Scenarios description and model input parameters.

\begin{tabular}{|c|c|c|c|c|c|}
\hline Parameters & Baseline & Scenario 1 & Scenario 2 & Scenario 3 & Scenario 4 \\
\hline Population increasing rate, $\%$ & 0.5 & 0.5 & 0.5 & 0.5 & 0.5 \\
\hline $\mathrm{BOD}_{5}, \mathrm{~g} /$ person/day & $40 \sim 60$ & $40 \sim 60$ & $40 \sim 60$ & $40 \sim 60$ & $40 \sim 60$ \\
\hline \multicolumn{6}{|l|}{ Wastewater discharge pathways, $T_{k, j} \%$} \\
\hline (i) Latrines & 80 & 20 & 20 & 20 & 20 \\
\hline (ii) Sewer & - & 10 & 10 & 10 & 10 \\
\hline (iii) Conventional activated sludge & - & 50 & 20 & - & 20 \\
\hline (iv) Johkasou & - & - & 30 & 50 & 30 \\
\hline (v) Others & 20 & 20 & 20 & 20 & 20 \\
\hline Energy consumption for CAS [24], kWh/person/year & 30 & 30 & 30 & 30 & 30 \\
\hline Energy consumption for Johkasou, $\mathrm{kWh} /$ person/year & 88 & 88 & 88 & 75 & 75 \\
\hline
\end{tabular}

(IPCC Fourth Assessment Report, B1 family scenario: rapid economic growth, but with rapid changes towards a service and information economy; global population reaching the peak in 2050 and declining thereafter; reductions in material intensity and the introduction of clean and resource-efficient technologies; the emphasis on global solutions to economic, social, and environmental sustainability (low emission scenario).)).

In the baseline scenario set until 2041, the proportion of rural population having access to hygienic latrine is $80 \%$; there are no wastewater sewers to collect wastewater. The major source of methane emission is from wastewater treated in household latrines. In scenario 1, twenty percent of rural population has access to hygienic latrine, $10 \%$ wastewater is collected by sewer, and $50 \%$ is treated with conventional aerobic treatment. Scenarios 2 and 4 exhibit that the Japanese Johkasou wastewater treatment could be introduced and served for $30 \%$ of the rural households by the year 2041 . The proportion of rural population having access to hygienic latrine is $20 \%$. The distributions of $10 \%$ and $20 \%$ wastewater of the rural population wastewater are collected by sewer and treated with aerobic treatment, respectively. Scenario 3 assumes that $50 \%$ of domestic wastewater discharged from total population will be treated in Johkasou system.

Electricity consumption for wastewater treatment with conventional activated sludge is $30 \mathrm{kWh} / \mathrm{cap} /$ year while energy consumption for Johkasou is $88 \mathrm{kWh} /$ capita/year. In scenarios 3 and 4 , energy consumption in Johkasou is reduced to $75 \mathrm{kWh} /$ capita/year, and this reduction results from technology innovation and introducing of low energy Johkasou. The electricity source is from national grid with emission factor of 0.56 to $0.72 \mathrm{tCO}_{2} / \mathrm{MWh}$ in years 2012 and 2041, respectively, except that in scenario 4 emission factor is $0.66 \mathrm{tCO}_{2} / \mathrm{MWh}$ in year 2041. The grid emission reduction resulted from effectively implemented Green Growth Strategy in the power sector, with $8 \%$ reduction compared with baseline projection.

\section{Results and Discussions}

3.1. Methane Emission from Domestic Wastewater and Discharge: Baseline and Projection. A total number of 103 subwatersheds are studied for GHG emissions from domestic wastewater discharged by rural population living within the $\mathrm{Vu}$ Gia Thu Bon river basin. The area of watersheds ranges from 2.4 to $93.2 \mathrm{~km}^{2}$. Table 4 shows ten watersheds with the highest GHG emissions, in a period of 30 years. Even though these watersheds represent only $17 \%$ of the total area, they attribute to $49 \%$ of total GHG emissions from wastewater.

Baseline Scenario. As shown in Figure 8(b) and Table 5, based on the emission model output, total GHG emissions from wastewater in the area are 2.7 million $\mathrm{tCO}_{2}$ eq for the 30year project. An emission from wastewater per capita per year is $2.7 \%$ of total GHG emissions projection per capita in 2030 which is $5.0 \mathrm{tCO}_{2}$ eq (Vietnam's Second National Communication to UNFCCC, 2010).

Project Scenario 1. Figure 9(a) and Table 5 show that, by 2041, the major source of GHG emissions is from wastewater treated in household latrines, with some proportion of methane gas emitted from the sewer. Total emissions from wastewater in the area are 2.17 million $\mathrm{tCO}_{2}$ eq for the total 30 years' simulation. The emissions from wastewater per capita per year are $0.11 \mathrm{tCO}_{2}$ eq. By treatment of wastewater, the total methane emission reduction is 0.59 million $\mathrm{tCO}_{2} \mathrm{eq}$, which is $21 \%$ reduction compared with the baseline scenario.

Project Scenario 2. Figure 9(b) and Table 5 indicate that sources of GHG emissions are from wastewater treated in household latrines, with GHG emitted from the sewer and from Johkasou treatment system. Total emissions from wastewater in the area are 2.33 million $\mathrm{tCO}_{2}$ eq for the total 30 years' simulation. Emissions from wastewater per capita per year are $2.3 \%$ of total GHG emissions per capita in 2030 and the GHG emissions reduction for this project scenario is $12 \%$ compared with baseline scenario.

Project Scenario 3. Figure 9(c) and Table 5 show that the total amount of GHG emissions from wastewater in the area for the period of 30 years is 2.42 million $\mathrm{tCO}_{2}$ eq. Compared with baseline scenario, emissions reduction for 30-year simulation period is 0.33 million $\mathrm{tCO}_{2}$ eq which accounted for $12 \%$.

Project Scenario 4. Figure 9(d) and Table 5 indicate that the major source of GHG emissions is from wastewater treated in household latrines, from sewer, and from Johkasou treatment 
TABLE 4: GHG emissions projection from 10 most populated watersheds.

\begin{tabular}{|c|c|c|c|c|c|c|c|c|}
\hline \multirow{2}{*}{ ID } & \multirow{2}{*}{$\begin{array}{l}\text { Residential area, } \\
\mathrm{km}^{2}\end{array}$} & \multicolumn{2}{|c|}{ Population 2041} & \multicolumn{5}{|c|}{$\mathrm{CH}_{4}$ emissions from wastewater, $\mathrm{tCO}_{2} \mathrm{eq}$} \\
\hline & & People & People $/ \mathrm{km}^{2}$ & Baseline & S1 & S2 & S3 & S4 \\
\hline 1 & 9.95 & 79,620 & 8,003 & 336,508 & 258,197 & 270,273 & 317,945 & 269,425 \\
\hline 2 & 14.26 & 73,418 & 5,149 & 310,295 & 238,084 & 249,220 & 269,721 & 248,438 \\
\hline 3 & 5.12 & 26,389 & 5,149 & 111,533 & 85,577 & 89,580 & 96,949 & 89,299 \\
\hline 4 & 8.54 & 23,885 & 2,798 & 100,949 & 77,456 & 86,943 & 87,749 & 85,716 \\
\hline 5 & 10.70 & 22,013 & 2,057 & 93,461 & 71,361 & 80,104 & 80,847 & 78,973 \\
\hline 6 & 25.09 & 19,426 & 774 & 79,625 & 63,773 & 68,233 & 68,888 & 67,236 \\
\hline 7 & 7.69 & 15,813 & 2,057 & 67,488 & 51,219 & 57,500 & 58,034 & 56,688 \\
\hline 8 & 28.85 & 15,067 & 522 & 62,165 & 49,870 & 53,329 & 53,837 & 52,556 \\
\hline 9 & 7.24 & 14,895 & 2,057 & 61,370 & 49,216 & 52,636 & 53,139 & 51,871 \\
\hline 10 & 4.10 & 14,668 & 3,578 & 61,994 & 47,567 & 53,393 & 53,888 & 52,639 \\
\hline
\end{tabular}

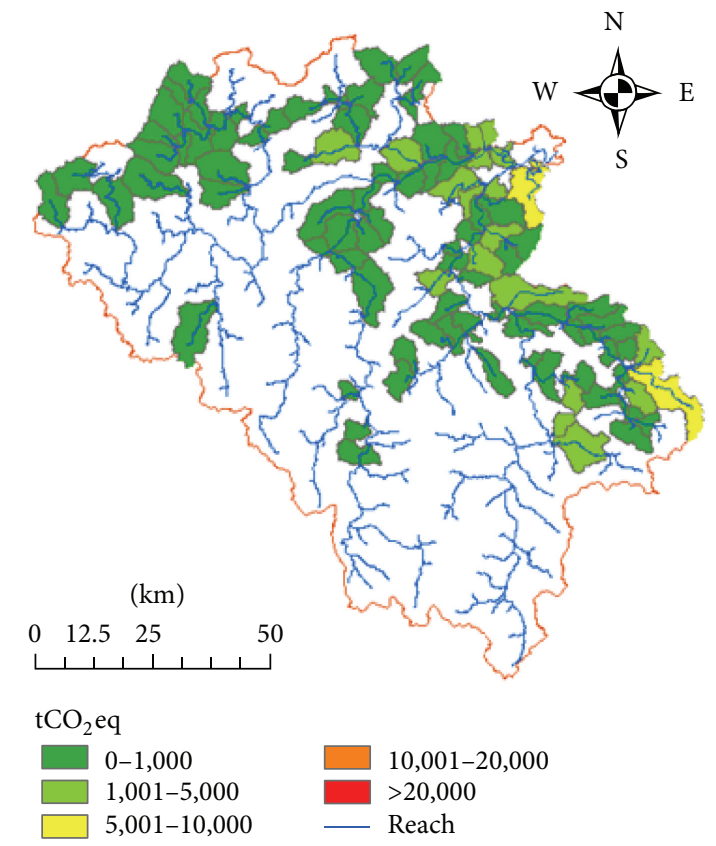

(a)

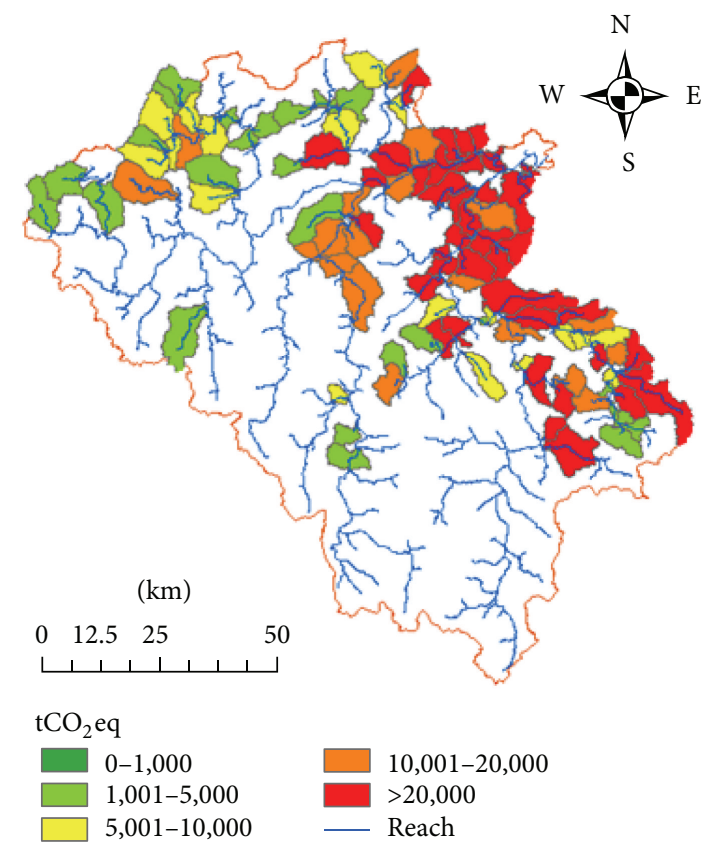

(b)

FIGURE 8: GHG emissions from domestic wastewater. (a) Inventory year 2012. (b) Baseline scenario for period of 30 years.

TABLE 5: Total GHG emissions from 103 watersheds.

\begin{tabular}{|c|c|c|c|c|c|}
\hline Parameters & Baseline & $\mathrm{S} 1$ & S2 & S3 & S4 \\
\hline Total emission, & 2.76 & 2.17 & 2.33 & 2.42 & 2.31 \\
\hline $\begin{array}{l}\text { Emission reductions, mil } \\
\mathrm{tCO}_{2} \mathrm{eq}\end{array}$ & - & 0.59 & 0.42 & 0.33 & 0.45 \\
\hline on reductions, \% & - & 21 & 1. & 12 & 16 \\
\hline $\begin{array}{l}\text { Emission per capita per } \\
\text { year, } \mathrm{tCO}_{2} \text { eq }\end{array}$ & 0.15 & 0.11 & 0.12 & 0.13 & 0 . \\
\hline
\end{tabular}

system. The emission model generates total amount of methane emissions from wastewater in the area for period of 30 years being 2.31 million $\mathrm{tCO}_{2}$ eq. Compared with baseline scenario, emissions reduction for project period is 0.45 million $\mathrm{tCO}_{2}$ eq and the $\mathrm{GHG}$ emissions reduction per capita per year from wastewater is $0.12 \mathrm{tCO}_{2} \mathrm{eq}$.

3.2. Uncertainties. The IPCC guideline employed in this study suggests several parameters in the model, which are believed to be very uncertain such as maximum $\mathrm{CH}_{4}$ producing capacity, the collection of additional industrial BOD discharged in the system. In addition the wastewater treatment pathways in the areas are assumed; however it is highly uncertain with public acceptance. Therefore, acceptance to have Johkasou system installed in household or group of households that replaced local household latrines is considered. With uncertainty level of $\pm 10 \%$ of population acceptance to install Johkasou instead of conventional household latrines, total GHG emissions will range from $\pm 2 \%$ (scenarios 2 and 3) to $15-22 \%$ (scenario 4 ). 
TABLE 6: Investment (capital expenditure, CAPEX, and O\&M, OPEX) for the various wastewater treatment system.

\begin{tabular}{|c|c|c|c|}
\hline \multirow{2}{*}{ Type } & CAPEX & OPEX & \multirow{2}{*}{ Note } \\
\hline & \multicolumn{2}{|c|}{ USD/person/year } & \\
\hline Latrines & 3 & 0 & Common pour-flush latrine type \\
\hline Sewer & 22 & 5 & $\begin{array}{c}\text { Source: Hydroconseil, } 2013 \text { [25] } \\
\text { Estimated sewer CAPEX equals } 1.6 \text { times wastewater } \\
\text { treatment plant CAPEX }\end{array}$ \\
\hline $\begin{array}{l}\text { Conventional activated sludge } \\
\text { (CAS) }\end{array}$ & 14 & 12 & $\begin{array}{c}\text { Source: }[3] \\
1 \text { USD }=22,500 \text { VND }(2015) \\
\text { Wastewater discharge } 150 \text { litres/capita/d } \\
\text { Value for small scale wastewater treatment plant with } \\
\text { CAS }(\text { A2O) } \\
\text { Capacity }<10,000 \mathrm{~m}^{3} / \mathrm{d}\end{array}$ \\
\hline Johkasou & 17 & 6 & $\begin{array}{c}\text { Source: [26]. } \\
\text { Domestic Johkasou system for } 5 \text { persons }\end{array}$ \\
\hline
\end{tabular}

3.3. Investment Requirement. The investment aspect of various wastewater treatment system proposed was analyzed based on the investment per year for the 30-year lifetime. Estimated investment for various wastewater treatment system is presented in Table 6 .

The result shows that the baseline scenario requires smallest investment whereas scenario 1 with centralized wastewater treatment requires the largest investment which is 1.5 million and 18.7 million US dollars per year, respectively (Figure 10). The combination system comprises decentralized system (Johkasou and latrines) in the upper streams and centralized system (sewer and wastewater treatment plant) in the populated down streams of the $\mathrm{Vu}$ Gia Thu Bon river basin which can reduce investment cost to 9-13 million USD per year.

3.4. Discussions. Methane emission from domestic wastewater increased annually from 2012 to 2040 . By the year 2041 total methane emissions were 2.76 mil.tCO 2 eq and contribute $2.7 \%$ to total GHG emissions per person per year. According to simulation scenarios and economic analysis, the total GHG emissions can be reduced up to $16 \%$ compared to the baseline scenario for 30 years of project period. The increasing of $\mathrm{CH}_{4}$ emissions reduction resulting from the treatment of domestic wastewater was found in a study by Ma et al. [7], where the emissions reduction was $7.5 \%$. Also if the sludge removal from wastewater treatment was included in the scope of study, methane emissions reduction would increase. In particular, sludge from Johkasou system shall be collected and treated under proper sludge management technologies such as fertilizer for urban greening or manufacturing of building materials [9].

Scenario 4 targeting $30 \%$ of rural household installs Johkasou especially in the mountainous areas in the upper and middle stream of the $\mathrm{Vu}$ Gia Thu Bon river basin, where the population density is relatively lower than the downstream. In populated areas downstream, centralized, or semicentralized wastewater treatment system is favored and more efficient. However, reducing the cost for installation and maintenance was seen as the important factor to aim at large scale deployment of Johkasou. Because the initial investment puts burden on the household since the cost for installation is usually 10 to 100 times higher than the cost for latrines or septic tanks.

The first Johkasou treatment unit was introduced to Vietnam by the Kubota Corporation in 2007; up to date the number of projects using Johkasou is over 1000 projects, mostly for domestic wastewater treatment at public entities (district level hospitals). Regarding the small size Johkasou for household wastewater treatment, there are few projects except for some feasibility studies, because of the high installation costs. With this development process, despite of the advanced technology of Johkasou, it is hardly implemented in the large scale. The similar issue of large scale deployment of Johkasou in developing country like Vietnam was discussed in the report from JICA [31]. To achieve Johkasou commercialization in the region, it is necessary to reduce the price for Johkasou system and meanwhile establish the carbon offsetting scheme. In particular, the emission offsetting from large scale installation of Johkasou for the region would reduce the initial cost. The target of $30 \%$ of household installing Johkasou in the Vu Gia Thu Bon river basin would likely be achieved in the condition of receiving financial support from government funding, ODA, international climate crediting schemes, and other international organization and private entities.

\section{Conclusions}

GHG emissions reduction can be achieved through treatment of domestic wastewater to achieve low-carbon watershed. Compared with baseline scenario, a maximum of $16 \%$ of total GHG emissions can be reduced in scenario 4, in which Johkasou replacing $30 \%$ of household latrines and $20 \%$ of domestic wastewater is treated by conventional activated sludge based on the projection. Emissions reduction from wastewater treatment can be credited to existing carbontrading scheme, in order to minimize the initial cost of system construction including installation of Johkasou. On the other hand, GHG emissions can also be reduced by utilizing renewable energy for wastewater treatment which eliminates grid emissions. High uncertainty of emission calculation 

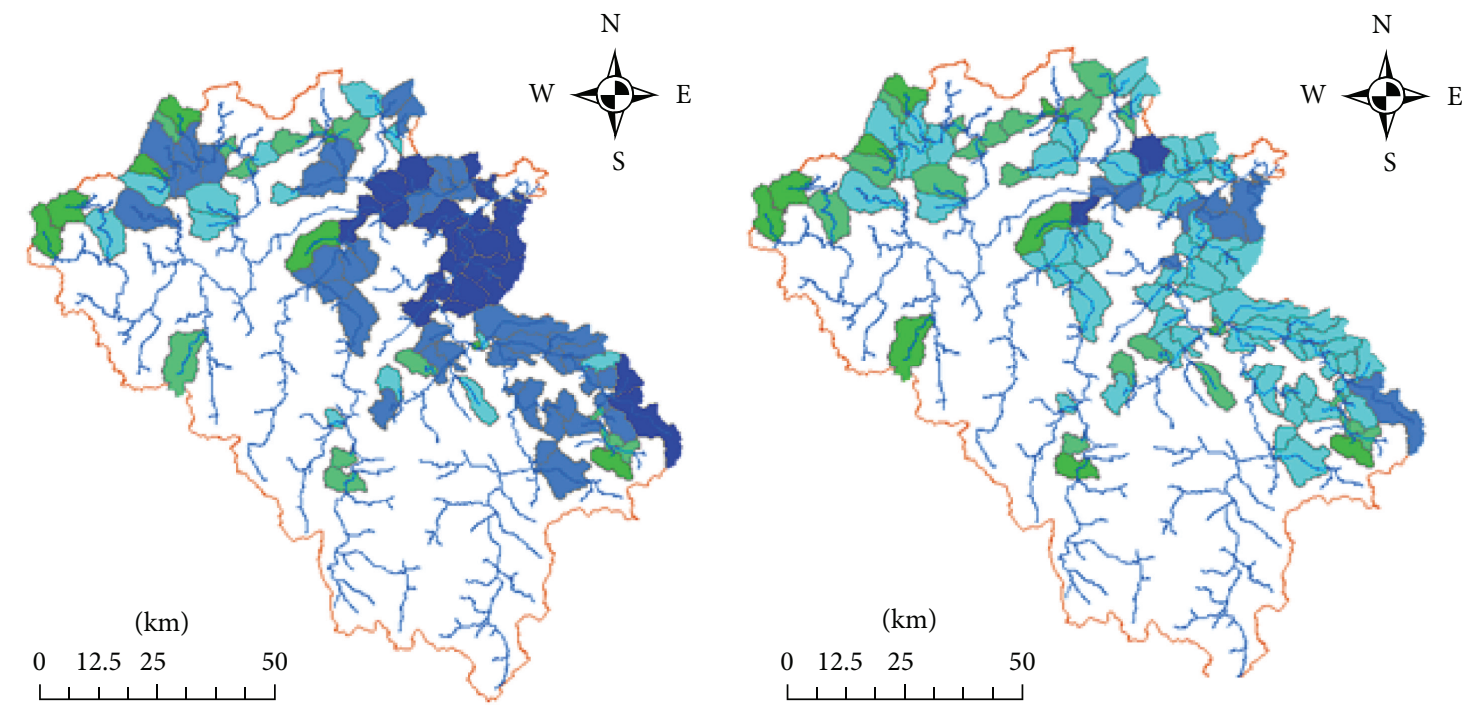

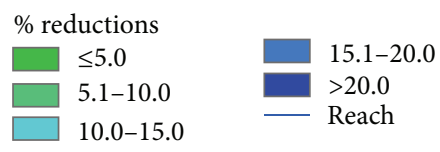

(a)

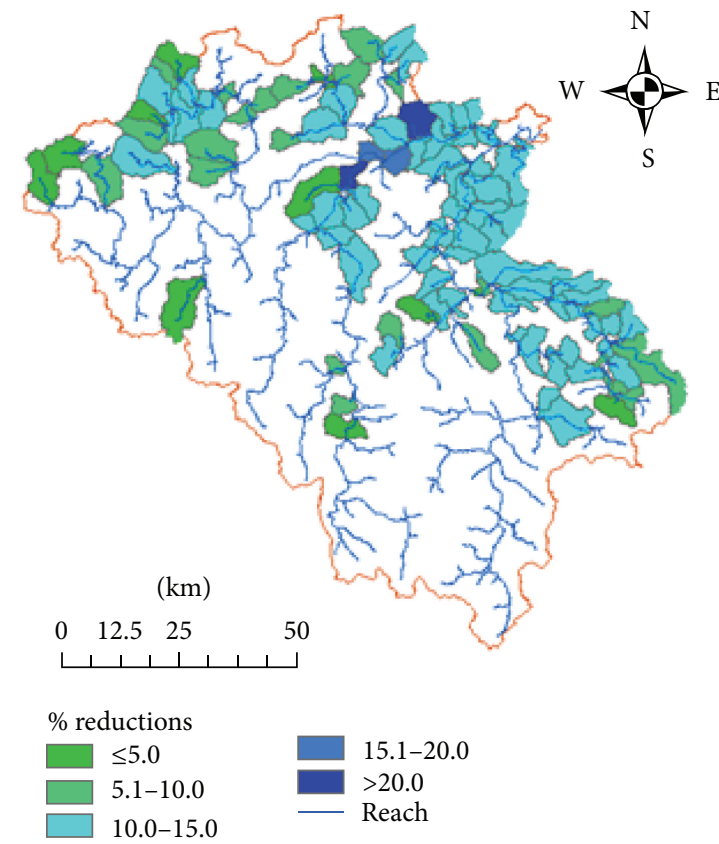

(c)

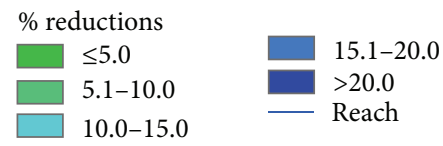

(b)

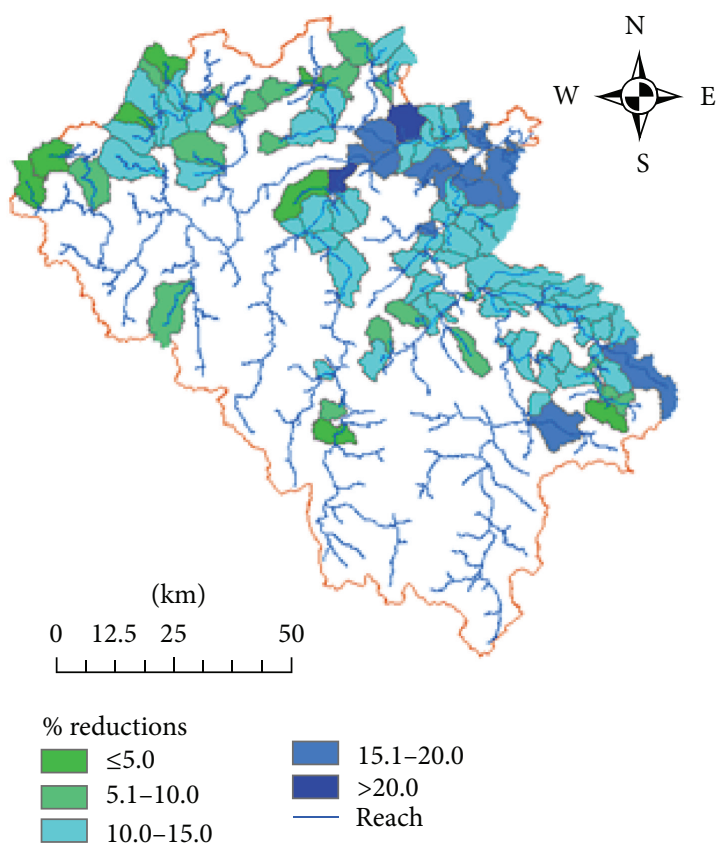

(d)

FIGURE 9: GHG emissions reduction with baseline (in percentage) from domestic wastewater treatment. (a) Scenario 1. (b) Scenario 2. (c) Scenario 3. (d) Scenario 4.

can be minimized by accessibility of local data or existing empirical data.

The research finding indicates that government's GHG emissions reduction target in the waste sector can be set up to $16 \%$. Moreover, a method to develop emission inventory for wastewater treatment in rural areas of developing countries from the watershed approach is proposed. In addition, this study raises the potential of utilizing existing carbon emission trading schemes for initial investment of the wastewater treatment facilities through carbon credit.

\section{Competing Interests}

The authors declare that they have no competing interests. 


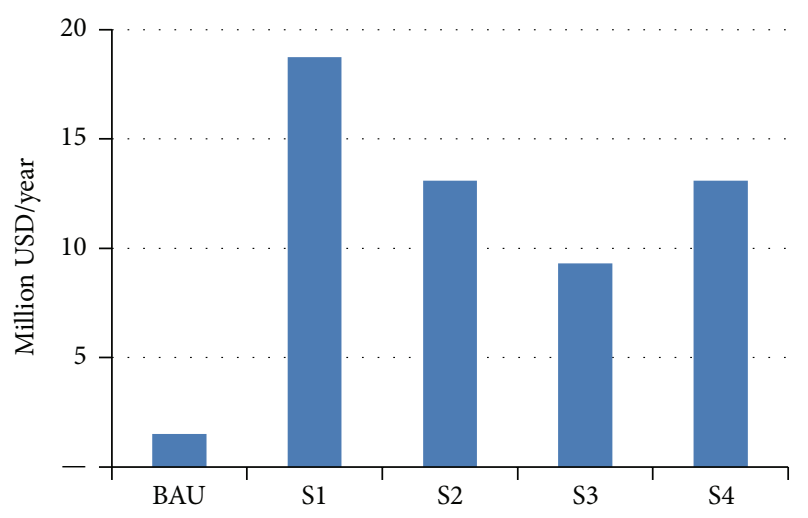

FIGURE 10: Investment for wastewater treatment system.

\section{Acknowledgments}

This study is partially supported by KAKENHI (26303012, P.I. Kensuke Fukushi) through JSPS. The study is conducted under GPSS-GLI and sponsored by GLI fellowship at University of Tokyo funded by the Ministry of Education, Culture, Sports, Science and Technology (MEXT) of the Japanese Government.

\section{References}

[1] Ministry of Environmental and Natural Resources, Vietnam's Second National Communication to the UNFCCC, Ministry of Environmental and Natural Resources, 2010.

[2] J. Bogner, R. Pipatti, S. Hashimoto et al., "Mitigation of global greenhouse gas emissions from waste: conclusions and strategies from the Intergovernmental Panel on Climate Change (IPCC) Fourth Assessment Report. Working Group III (Mitigation)," Waste Management and Research, vol. 26, no. 1, pp. 11-32, 2008.

[3] WHO, IHEMA, and Unicef, Vietnam Water and Sanitation Sector Assessment Report, WHO, IHEMA and Unicef, 2012.

[4] IPCC, Waste, vol. 5 of 2006 IPCC Guidelines for National Greenhouse Gas Inventories, Prepared by the National Greenhouse Gas Inventories Programme, IGES, Hayama, Japan, 2006.

[5] M. Doorn, D. Liles, and S. Thorneloe, "Quantification of methane emissions from latrines, septic tanks, and stagnant, open sewers in the world," in Non-CO ${ }_{2}$ Greenhouse Gases: Scientific Understanding, Control and Implementation, J. van Ham, A. P. M. Baede, L. A. Meyer, and R. Ybema, Eds., pp. 83-88, Springer, Berlin, Germany, 2000.

[6] VGGS, "Decision on the approval of the national green growth strategy. Prime Minister, Socialist Republic of Vietnam, No. 1393/QĐ-TTg," 2012.

[7] Z.-Y. Ma, P. Feng, Q.-X. Gao, Y.-N. Lu, J.-R. Liu, and W.T. $\mathrm{Li},{ }^{\circ} \mathrm{CH}_{4}$ emissions and reduction potential in wastewater treatment in China," Advances in Climate Change Research, vol. 6, no. 3-4, pp. 216-224, 2015.

[8] J. N. Galloway, R. W. Howarth, A. F. Michaels, S. W. Nixon, J. M. Prospero, and F. J. Dentener, "Nitrogen and phosphorus budgets of the North Atlantic Ocean and its watershed," Biogeochemistry, vol. 35, no. 1, pp. 3-25, 1996.

[9] B. Liu, Q. Wei, B. Zhang, and J. Bi, "Life cycle GHG emissions of sewage sludge treatment and disposal options in Tai Lake
Watershed, China," Science of the Total Environment, vol. 447, pp. 361-369, 2013.

[10] S. Brown, N. Beecher, and A. Carpenter, "Calculator tool for determining greenhouse gas emissions for biosolids processing and end use," Environmental Science and Technology, vol. 44, no. 24, pp. 9509-9515, 2010.

[11] A. Siddiqi and L. D. Anadon, "The water-energy nexus in Middle East and North Africa," Energy Policy, vol. 39, no. 8, pp. 4529-4540, 2011.

[12] T. Shah, "Climate change and groundwater: India's opportunities for mitigation and adaptation," Environmental Research Letters, vol. 4, no. 3, Article ID 035005, 2009.

[13] F. Kahrl and D. Roland-Holst, "China's water-energy nexus," Water Policy, vol. 10, no. 1, pp. 51-65, 2008.

[14] H. Furumai, "Life cycle energy analysis of water use system in Ara river watershed," in Proceedings of the IWA Workshop on Water and Energy \& Water Loss, Tokyo, Japan, April 2014.

[15] S. J. Kenway, A. Priestley, S. Cook et al., Energy Use in the Provision and Consumption of Urban Water in Australia and New Zealand, Water for a Healthy Country National Research Flagship, CSIRO, 2008.

[16] S. G. S. A. Rothausen and D. Conway, "Greenhouse-gas emissions from energy use in the water sector," Nature Climate Change, vol. 1, no. 4, pp. 210-219, 2011.

[17] UN's Joint Monitoring Programme for Water Supply and Sanitation, "Vietnam Country file," 2015.

[18] N. T. Nguyen, "Status and options for water supply management in Vietnam," 2009, http://www.moc.gov.vn/en/trangchi-tiet/-/tin-chi-tiet/Z2jG/86/30459/cong-tac-quan-ly-cap-nuoctai-cac-do-thi-viet-nam-thuc-trang-va-giai-phap.html.

[19] General Statistics Office, Statistical Yearbook of Vietnam 2012, 2013.

[20] Quang Nam Statistics Office, Quang Nam Statistical Year Book 2012, 2013.

[21] H. U. Tran and D. H. Tran, Small-Scale Wastewater Treatment by MBR for Domestic and Industrial Purpose: Design and Installation-Research Project under Ministry of Trade, 2013.

[22] Kubota Vietnam, "Standard design for Johkasou models using MBR for domestic wastewater treatment," 2016.

[23] Ministry of Natural Resources and Environment, "National technical regulation on domestic wastewater," QCVN 14:2008/BTNMT, Ministry of Natural Resources and Environment, 2011.

[24] D. Mara, Domestic Wastewater Treatment in Developing Countries, Earthscan, Washington, DC, USA, 2004.

[25] World Bank, "Vietnam urban wastewater review," Tech. Rep. ACS7712, 2013, https:/openknowledge.worldbank.org/bitstream/ handle/10986/17367/ACS77120v20REP010with0report0number .pdf? sequence $=1$.

[26] Hactra Vietnam, "Q\&A: Johkasou application for onsite wastewater treatment in Vietnam," 2016.

[27] Japan Education Center for Environmental Sanitations, Wastewater Treatment with Johkasou System, 2011.

[28] Y. Ebie, H. Yamazaki, S. Inamura, Y. Jimbo, T. Kobayashi, and H. Ueda, "Development of emissions factor for the decentralized domestic wastewater treatment for the national greenhouse gas inventory," Journal of Water and Environment Technology, vol. 12, no. 1, pp. 33-41, 2014.

[29] Japan Environment Association, Johkasou (Domestic Wastewater Treatment Tank), Certification Criteria, 2012. 
[30] L. H. Nguyen, Low-carbon watershed management: integration of renewable energy supply and decentralized wastewater treatment-a case study in Vietnam [Ph.D. thesis], 2016.

[31] Mitsubishi UFJ Research and Consulting JICA, Project for Leapfrog Development in Waste and Wastewater Sector, Mitsubishi UFJ Research and Consulting, Tokyo, Japan, 2014. 

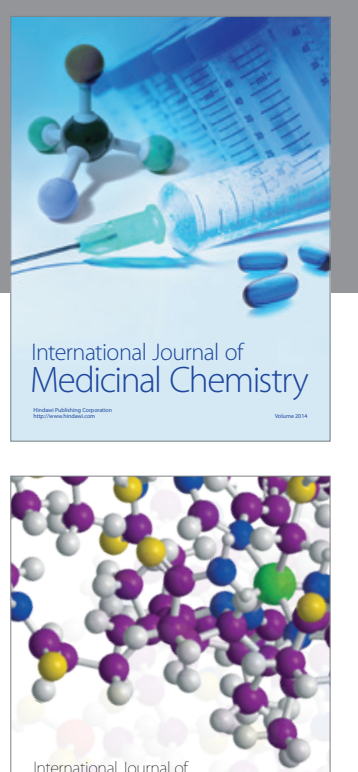

Carbohydrate Chemistry

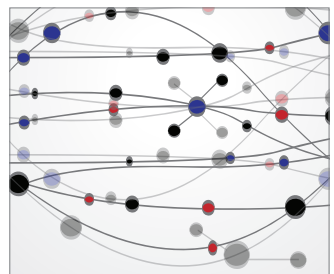

The Scientific World Journal
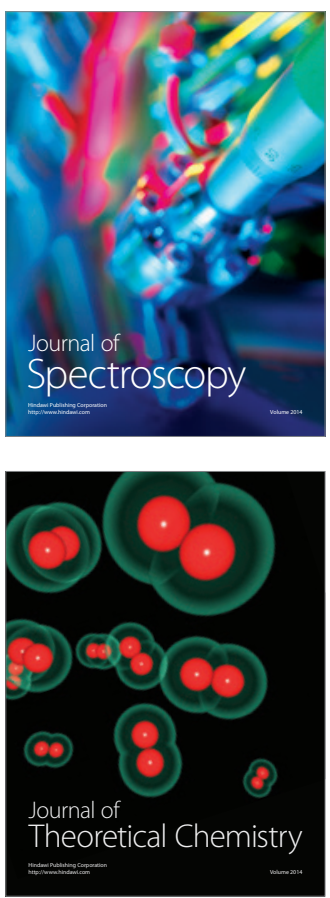
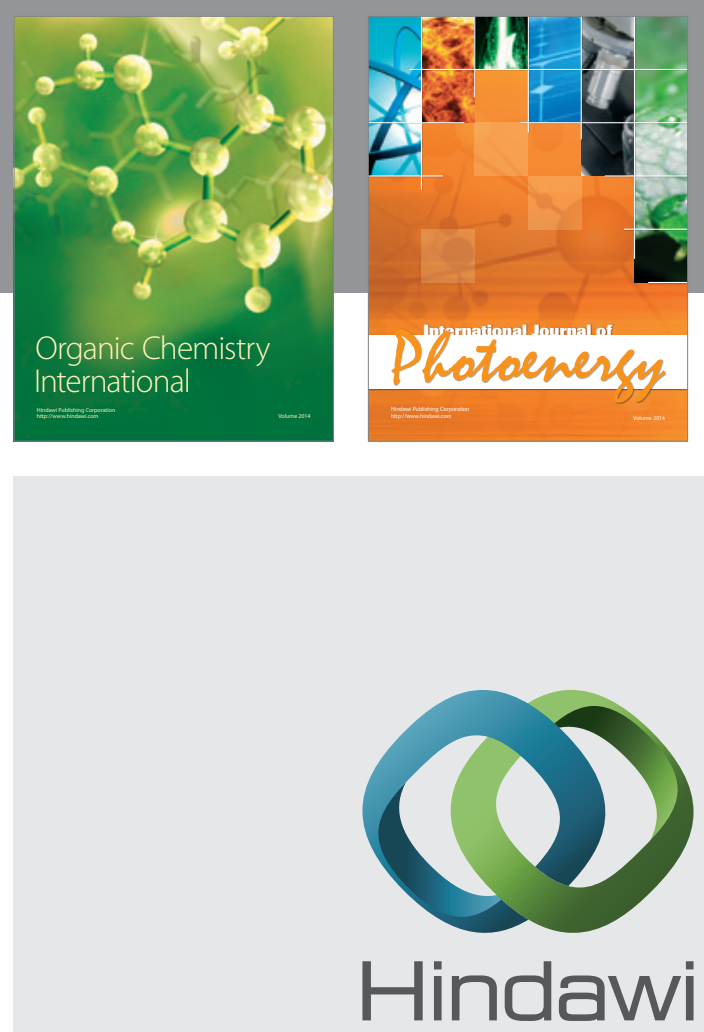

Submit your manuscripts at

http://www.hindawi.com

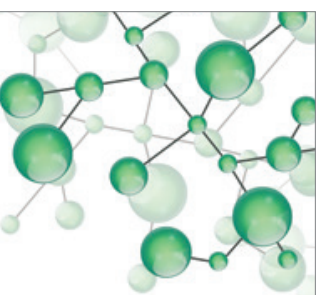

International Journal of

Inorganic Chemistry

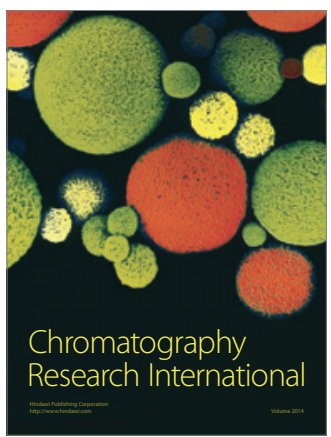

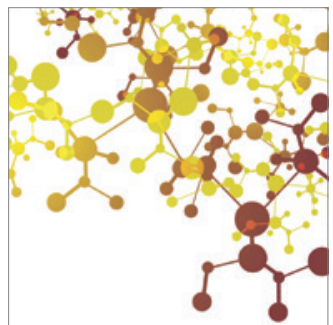

Applied Chemistry
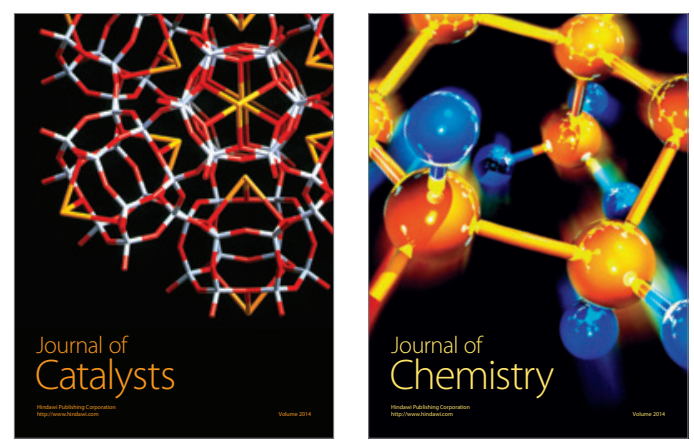
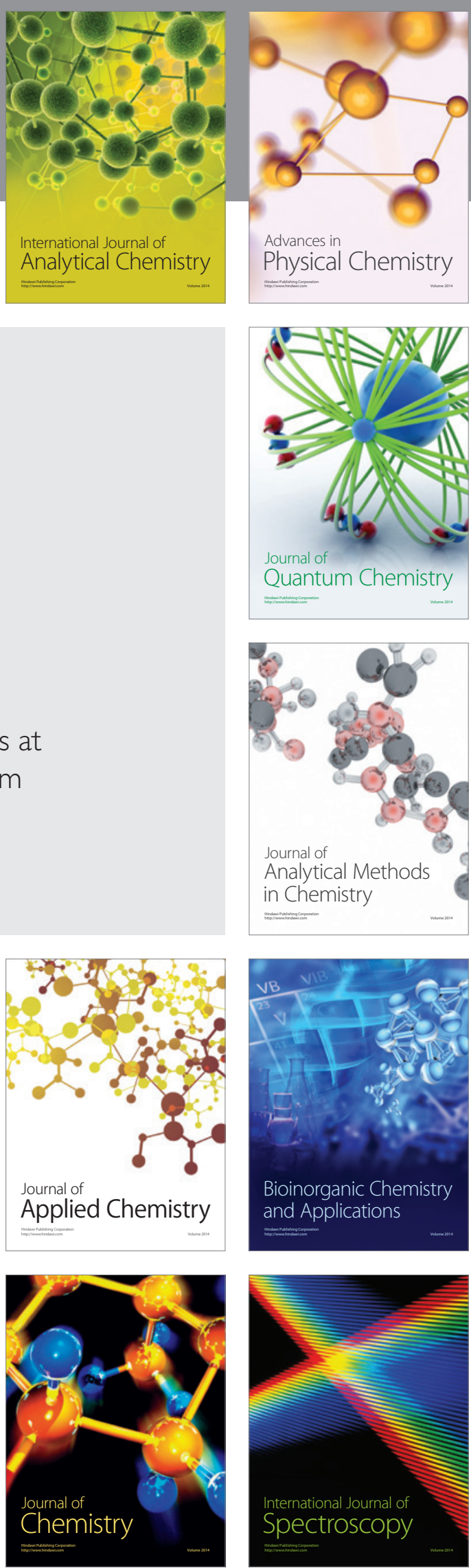